\title{
Cost Effectiveness of Insulin Glargine versus Neutral Protamin Hagedorn Insulin in the Treatment of Type 2 Diabetes Patients in Turkey
}

Ilhan Satman ${ }^{1}$, Hayley Bennett ${ }^{2}$, Candeger Yilmaz ${ }^{3}$, Sazi Imamoglu ${ }^{4}$, Goksun Ayvaz Abdurrahman Comlekci ${ }^{6}$, Demet Ozkaya ${ }^{7}$, Toros Sahin ${ }^{7}$

${ }^{1}$ Division of Endocrinology, Faculty of Internal Medicine, Istanbul University, Istanbul, Turkey

${ }^{2}$ Swansea Centre for Health Economics, Swansea University, Swansea, UK

${ }^{3}$ Division of Endocrinology, Faculty of Internal Medicine, Ege University, Izmir, Turkey

${ }^{4}$ Division of Endocrinology, Faculty of Internal Medicine, Uludag University, Bursa, Turkey

${ }^{5}$ Division of Endocrinology, Faculty of Internal Medicine, Gazi University, Ankara, Turkey

${ }^{6}$ Division of Endocrinology, Faculty of Internal Medicine, Dokuz Eylul University, Izmir, Turkey

${ }^{7}$ Sanofi Turkey, Istanbul, Turkey

Corresponding author: H.S.Bennett@Swansea.ac.uk

\section{Abstract}

Background: Type 2 diabetes mellitus (T2DM) poses a significant burden on population well being and healthcare expenditure in Turkey, with disease prevalence continuing to increase. Insulin treatment is necessary for patients failing to achieve glycaemic control with lifestyle modification or oral antidiabetic drugs. While neutral protamin Hagedorn (NPH) insulin has been traditionally prescribed for insulin introduction, insulin glargine has been shown to reduce glycated hemoglobin (HbA1c) with a more favourable hypoglycaemic profile.

Objective: To evaluate the cost-effectiveness of insulin glargine compared to NPH insulin in patients with T2DM in Turkey, from a Social Security Institution perspective.

Methods: A previously published discrete event simulation model of T2DM progression was utilised to characterise the cost-effectiveness of insulin glargine in a Turkish population given the benefits observed in clinical practice. Improvements in glycaemic control have been incorporated using data from The Health Improvement Network (THIN) database in the United Kingdom, combined with meta-regression results describing the relationship between hypoglycaemia and glycaemic control. Outcomes were evaluated over a 40-year horizon, and costs and benefits discounted at an annual rate of 3.5\%. Results are reported in Turksih lira (TL), 2012.

Results: Over a lifetime, the Incremental Cost-effectiveness Ratio (ICER) of insulin glargine compared to NPH was 40,101 TL per Quality-adjusted Life Year (QALY). Almost 52 hypoglycaemic events per patient were avoided with the use of insulin glargine compared to NPH, at an incremental lifetime cost of 7,140 TL per patient. The cost-effectiveness of insulin glargine is reduced when modelling only those benefits considered in the trial setting, while the cost-effectiveness profile can be expected to further improve in patients with higher HbA1c levels at baseline.

Conclusion: It is difficult to interpret the results of modelling as there is no official cost-effectiveness threshold in Turkey. However, the results may be evaluated using thresholds derived according to methodology proposed by the World Health Organisation (WHO). Insulin glargine is expected to be cost-effective compared to NPH insulin, with an ICER below three times the estimated gross domestic product (GDP) per capita; 56,850 TL.

Keywords: cost effectiveness, insulin glargine, NPH insulin, type 2 diabetes, Turkey 


\section{INTRODUCTION}

The prevalence of diabetesisincreasing rapidlyworldwide, with lifestyle changes andimprovedeconomicconditions contributing factors to the substantial risein patient numbers. Accordingto recentInternational Diabetes Federation (IDF) estimates, the total number of people with diabetes will rise from 366 million in 2011 (8.3\%) to 552 million by 2030, a prevalence rate of 9.9\%. ${ }^{1}$ The second Turkish Diabetes Epidemiology Study (TURDEP-II) found a higher prevalence rate of $16.5 \%$ in the Turkish population in 2010 (approximately 6.5 million), with an additional $14.5 \%, 7.9 \%$ and $8 \%$ prevalence of isolated impaired fasting glucose (IFG), impaired glucose tolerance (IGT) and pre-diabetes. ${ }^{2}$ It has previously been estimated that in Turkey, 300,000 individuals develop diabetes each year. ${ }^{3}$

In 2008, diabetes was the cause of death in approximately $2.2 \%$ of the Turkish population and the fourth major contributor to health expenses. The Turkish Diabetes Foundation estimated that annual treatment costs varied between approximately $€ 340$ in diabetic patients without any complications, to $€ 880$ in those with complications. ${ }^{4}$

A stepwise approach is conventionally taken in the management of type 2 diabetes mellitus (T2DM), in which more intensive strategies are required as the condition progresses. If optimal glycaemic control cannot be achieved through lifestyle modifications alone, progression to oral antidiabetic drugs (OADs) and insulin becomes necessary. ${ }^{5}$ Good glycaemic control is important in the prevention of chronic complications associated with diabetes, ${ }^{6}$ and can be improved by the timely initiation of insulin. ${ }^{7}$ The position statement of the American Diabetes Association (ADA) and European Association for the Study of Diabetes (EASD) recommends the addition of insulin therapy to lifestyle intervention strategies and metformin therapy, in patients with a glycated haemoglobin (HbA1c) level exceeding 7.0\%. ${ }^{8}$ Insulin analogues are being increasingly used in the treatment of diabetes in Turkey. ${ }^{9}$ The Society of Endocrinology and Metabolism of Turkey (SEMT) guidelines recommend therapy progression in patients with $\mathrm{HbA} 1 \mathrm{c}>6.5 \%$. The guidelines include insulin as a second-line therapy option for patients failing to achieve adequate glycaemic control with metformin alone, especially in those with $\mathrm{HbA} 1 \mathrm{c}>8.5 \% .^{10}$

However, in clinical practice the timely initiation of insulin therapy and achievement of glycaemic targets deviates from the recommendations presented in the guidelines. ${ }^{11}$ Indeed, the adherence of Turkish clinicians to the SEMT guidelines has been found inadequate, with negative impact on glycaemic control. ${ }^{12}$ Delays in the progression of treatment in the management of T2DM can result in extended periods of poor glycaemic control, which ultimately increase the risk of micro- and macro- vascular complications. ${ }^{13,14}$ Despite the efficacy of insulin therapy, concerns regarding the administration of injections, hypoglycaemia and weight gain ${ }^{15}$ fuel physician and patient reluctance to initiate insulin therapy. Hypoglycaemic events can be traumatic experiences with a substantial impact on quality of life. ${ }^{16}$ Furthermore, retrospective analysis of the Action to Control Cardiovascular Risk in Diabetes (ACCORD) trial study has found that symptomatic, severe hypoglycaemia is associated with an increased risk of mortality. ${ }^{17}$ Thus, there is a recognised trade-off between glycaemic control and hypoglycaemia risk.

There are still uncertainties regarding the optimal insulin treatment regimens for T2DM, but the long-acting insulin analogues seem promising. Patients failing on OADs have been shown to benefit from lower rates of hypoglycaemia and less weight gain when therapy with insulin glargine is initiated in early T2DM, compared with patients initiated on insulin therapy at later stages of the disease. ${ }^{18}$ A large body of clinical trial data has demonstrated the advantages of insulin glargine therapy in combination with OADs in patients with T2DM, compared with neutral protein Hagedorn (NPH) insulin. ${ }^{19}$ The intermediate-acting insulin, NPH insulin, has traditionally been used for insulin introduction in patients with T2DM. Many studies have found that 
patients treated with insulin glargine achieved similar HbA1c levels to those treated with NPH, but with a lower rate of hypoglycaemia in T2DM, ${ }^{19,20,21}$ while one trial reported an improvement in HbA1c. ${ }^{22}$

This study aims to assess the cost-effectiveness of T2DM treatment with insulin glargine compared to NPH insulin in Turkey, from a third party payer's perspective.

\section{METHODS}

\section{Model}

The economic model presented in this paper was based upon the model evaluated by the National Institute for Health and Clinical Excellence (NICE) in 2002 and has been described in detail elsewhere. ${ }^{23}$ In summary, the model is a discrete event simulation (DES) in which the progression of T2DM can be modelled for a cohort of up to 1,000 subjects, using annual time increments over the modelled time horizon of up to 40 years (Figure 1).

Figure 1. Flow Diagram of the T2DM Discrete Event Simulation Model

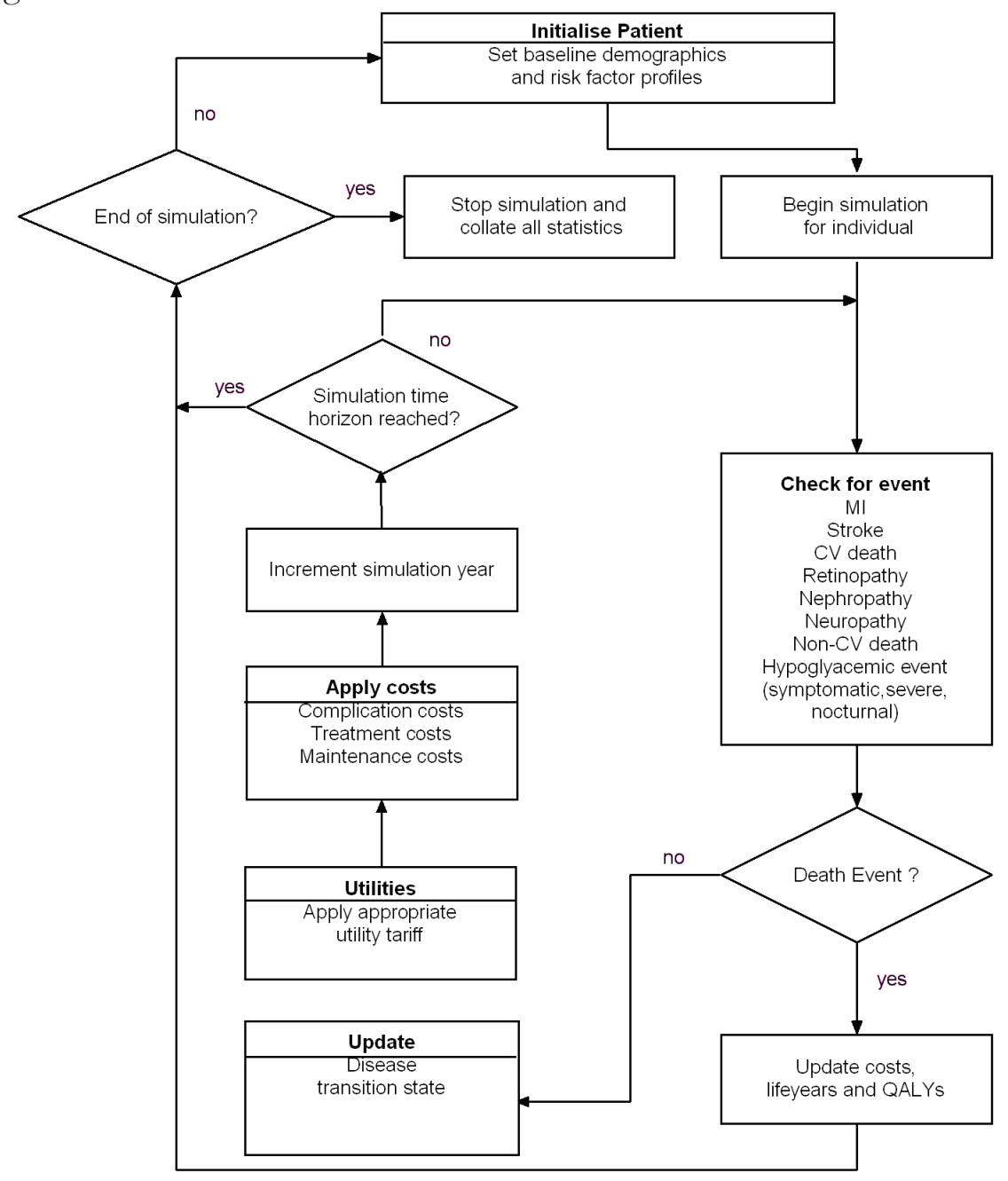

$\mathrm{MI}=$ myocardial infarction; $\mathrm{CV}=$ cardiovascular; $\mathrm{QALY}=$ quality-adjusted life year (score)

Modelling micro- and macro- vascular events in T2DM has been undertaken by encoding the UK Prospective Diabetes Study (UKPDS) $68^{24}$ equations for the prediction of diabetes-related complications; a series of Weibull proportional hazards regression equations. The model calculates the annual number of nocturnal, 
symptomatic and severe hypoglycaemic events expected and incorporates non-cardiovascular mortality via Turkish gender-specific life tables.

As the simulation progresses, the values of patient risk factors change thereby altering the likelihood of event occurrence over time. Possible treatment effects modelled are the improvement in glycaemic control and reduction in hypoglycaemic events.

\section{Data Inputs}

The mean demographic and baseline risk factor profile utilised in the base case analysis was based on the Turkish results for all T2DM patients in the International Diabetes Management Practice (IDMPS) study ${ }^{25}$ (Table 1).

Table 1. Baseline Characteristics of T2DM Patients in Turkey for the Base Case, Reported by Gordon et al ${ }^{27}$

\begin{tabular}{lcc}
\hline \multicolumn{1}{c}{ Variable } & Base Case & Gordon et al. \\
\hline Age (years) & 56.52 & 60.8 \\
Gender (\% female) & 57.0 & 45.6 \\
Duration with diabetes (years) & 8.19 & 6.2 \\
Weight (kg) & 80.74 & 85.3 \\
Height (metres) & 1.64 & Not reported \\
Total cholesterol (mmol/L) & 5.11 & Not reported \\
HDL cholesterol (mmol/L) & 1.29 & Not reported \\
Systolic blood pressure (mm Hg) & 129.51 & Not reported \\
HbA1c $\%)$ & 7.72 & 9.5 \\
Smoking $(\%)$ & 14.00 & Not reported \\
\hline
\end{tabular}

\section{Glycaemic Control}

Following its positive evaluation by NICE in 2002, glargine became an established basal insulin in the United Kingdom ${ }^{26}$ enabling the evaluation of glycaemic control in a large number of patients in a general clinical setting.

Model inputs have been informed by results of an analysis of UK practice patterns and patient outcomes data from The Health Improvement Network (THIN) database presented by Gordon et al. ${ }^{27}$ An in-depth comparison of patients newly prescribed insulin glargine, NPH, detemir, and premix insulin was conducted and multiple regression analysis used to model the primary outcome; change in HbA1c at 12 months. After adjustment for significant and clinical covariates, the reported reduction in HbA1c associated with glargine compared to NPH was $0.19 \%$. This value was applied in the base case analysis.

Total daily insulin dosages observed in the THIN database were lowest with glargine (basal/total: 0.56/0.66 $\mathrm{U} / \mathrm{kg} /$ day) and highest with NPH (basal/total: 0.64/0.81 U/kg/day). After adjusting for this difference in daily dosages, a larger difference in glycaemic control was found between glargine and NPH. Further subgroup analysis revealed greater improvement in glycaemic control in patients with a baseline HbA1c of at least 8\% and of at least $10 \%$ (Table 2). 
Table 2. Improvement in Glycaemic Control (HbA1c) at 12 months $^{\dagger}$ for Glargine versus NPH; before and after Dose Adjustments

\begin{tabular}{lcc}
\hline & HbA1c & Dose-adjusted HbA1c \\
\hline & Reduction $^{\dagger}$ at 12 months & Reduction at 12 months \\
\hline Overall & 0.19 & 0.30 \\
Baseline HbA1c $\geq 8 \%$ & 0.25 & 0.41 \\
Baseline HbA1c $\geq 10 \%$ & 0.27 & 0.47 \\
\hline
\end{tabular}

$\mathrm{HbA1}=$ glycated hemoglobin; ${ }^{\dagger} \mathrm{HbA} 1 \mathrm{c}$ reduction adjusted for age, sex, duration of diabetes, weight, number of oral therapies and comorbidities

\section{Relationship between HbA1c and Hypoglycaemia}

The model incorporates the annual probability of experiencing a severe hypoglycaemic event from the Diabetes Control and Complications Trial (DCCT), ${ }^{13}$ in addition to annual rates of nocturnal and symptomatic hypoglycaemic events sourced from Riddle et al. ${ }^{19,28}$ (Table 3). There is a recognised correlation between glycaemic control and the risk of hypoglycaemia and the nature of this relationship between HbA1c and hypoglycaemia has been characterised as shown in Figure 2.

Table 3. Estimated Annual Hypoglycaemia Risks and Number of Expected Events

\begin{tabular}{lcl}
\hline \multicolumn{1}{c}{ Hypoglycaemia } & Value & \multicolumn{1}{c}{ Source } \\
\hline Risk of Severe & ${ }^{\dagger} 0.462$ & DCCT, ${ }^{13}$ Leese et al. ${ }^{34}$ \\
Number of Nocturnal & 4.9 & Riddle et al. ${ }^{19}$ \\
Number of Symptomatic & 16.8 & Riddle et al. ${ }^{28}$ \\
\hline
\end{tabular}

tpredicted reduction for an equivalent risk of symptomatic hypoglycaemic episodes

Figure 2. Rate of Severe Hypoglycaemia in Patients Receiving Intensive Therapy; According to their Mean Glycosylated Haemoglobin Values during the DCCT Trial ${ }^{13}$

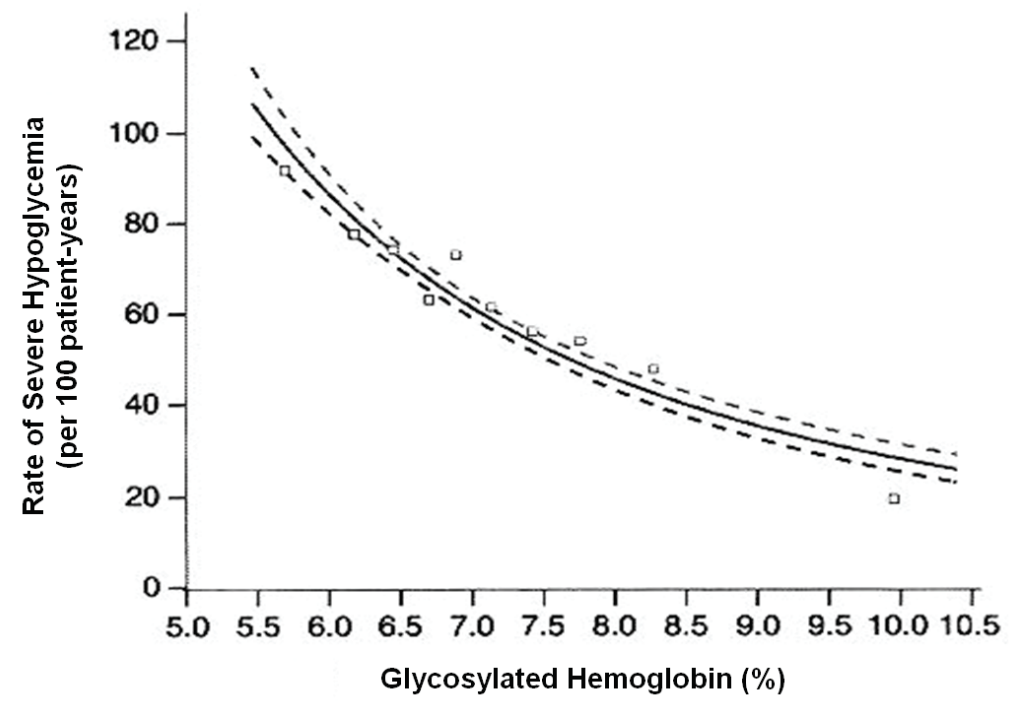

The reductions in hypoglycaemic events associated with glargine compared to NPH were taken from Mullins et al. ${ }^{29}(10 \%, 35 \%$, and $40 \%$ for symptomatic, nocturnal, and severe events respectively) and calibration 
coefficients were applied to the Mullins equations to automatically derive baseline hypoglycaemia rates dependent on HbA1c levels at baseline (Figure 3).

Figure 3. Illustrating Re-calibration of the Mullins Meta-regression Equations; for Setting HbA1c-specific Levels of Baseline Hypoglycaemia

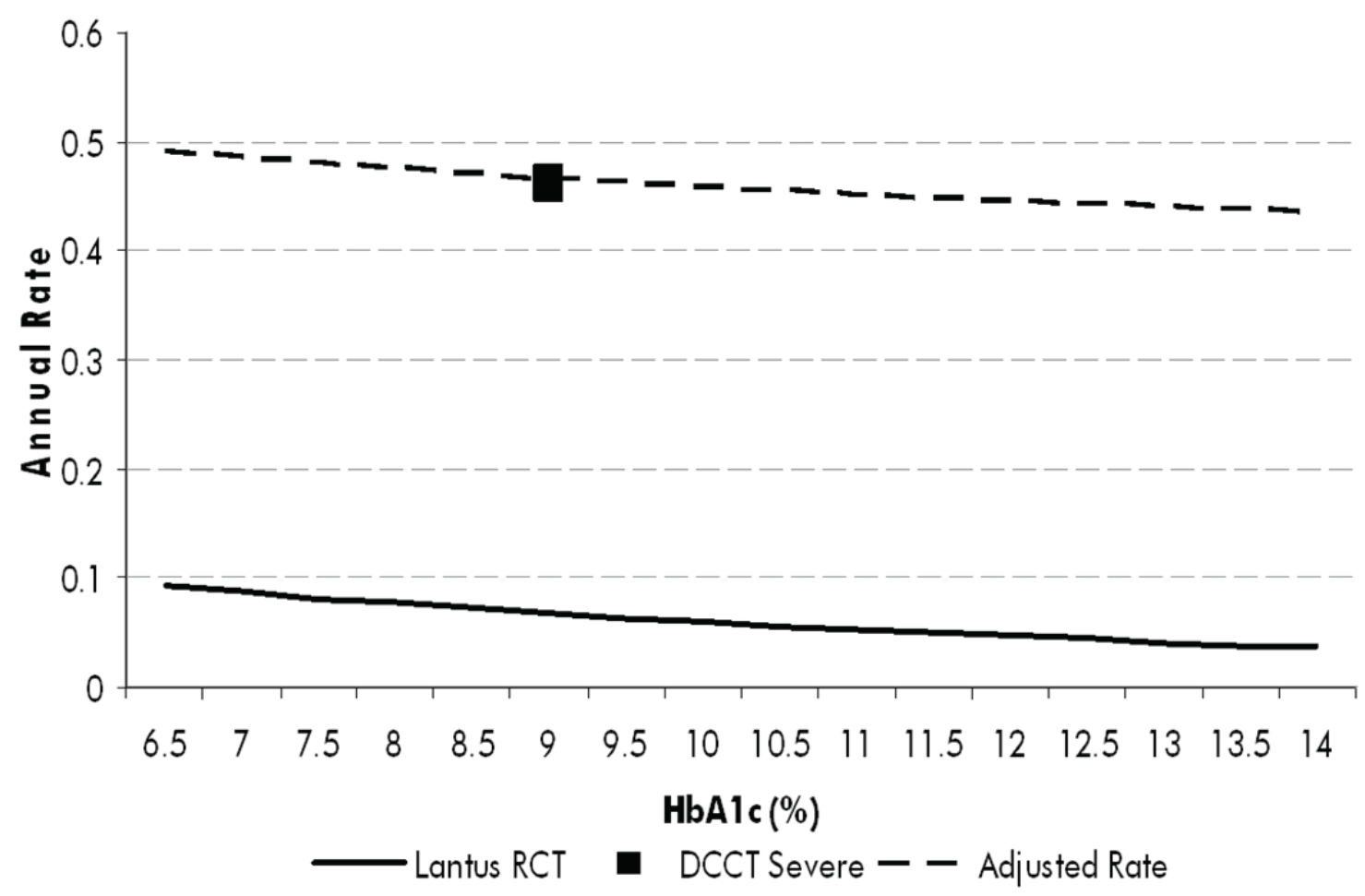

RCT $=$ randomised control trial; DCCT $=$ Diabetes Control and Complications Trial; HbA1c $=$ glycated hemoglobin

\section{Costs}

All costs applied in the model are presented in 2012 Turkish Lira (TL), adjusted for inflation using International Monetay Fund (IMF) price indices for Turkey where required. ${ }^{30}$

The official price list was used to inform unit costs of insulin glargine and NPH. ${ }^{31}$ In the base case analysis, treatment costs were applied according to the daily insulin dosages reported in Gordon $e t a l^{27}$ The costs applied to diabetes-related complications were derived via the opinions of a panel of Turkish experts, specialising in the fields of internal diseases/endocrinology, cardiology, eye diseases, neurology, orthopaedics/general surgery, and urology (Table 4). 
Table 4. Fatal and Non-fatal Event and Maintenance Costs Applied in the T2DM Model

\begin{tabular}{lccc}
\hline & \multicolumn{3}{c}{ Costs (TL) } \\
\hline Complication & Fatal & Non-fatal & Maintenance \\
\hline Macrovascular & & & \\
\hline Ischaemic Heart Disease & 3129.33 & 1851.06 & 727.04 \\
Myocardial Infarction & 3322.95 & 2022.35 & 684.56 \\
Congestive Heart Failure & 9717.60 & 1239.68 & 930.59 \\
Stroke & 929.00 & 996.25 & 1061.37 \\
\hline Microvascular & & & \\
\hline Retinopathy: Blindness & - & 956.82 & 740.29 \\
Renal: Dialysis & - & 27055.72 & 27055.72 \\
Amputation & 2159.96 & 2159.96 & 4582.44 \\
Severe Hypogiyacaemia & 74.64 & 74.64 & 0.00 \\
\hline
\end{tabular}

TL=Turkish Lira

Either fatal or non-fatal event costs are applied in the year of incidence, with annual maintenance costs applied in all subsequent years for non-fatal events. Maintenance costs associated with ischaemic heart disease and myocardial infarction could not be sourced; hence they were estimated by adjusting the cost of congestive heart failure maintenance according to the ratio observed in the United Kingdom.

As subjects are assumed to incur severe vision loss or blindness in both eyes simultaneously, the blindness event can occur only once. Dialysis costs are annual weighted mean costs for peritoneal and haemodialysis. A cost is applied to severe hypoglycaemic events only.

\section{Health-related Utility}

Decrements in health-related utility associated with diabetes-related complications were derived from the UKPDS 62 study $^{32}$ or generated via the Health Outcomes Data Repository (HODaR) database. ${ }^{33}$ The HODaR project collected patient data characterising demography, productivity, self-reported risk factors, and healthrelated quality of life (HRQoL) using the SF-36 and EQ-5D from patients discharged from the Cardiff and Vale NHS Trust, which treats the local population $(n=424,000)$ and acts as a tertiary centre for the rest of Wales (UK). Data were linked anonymously to routinely collected inpatient and outpatient data. Patients were excluded from the analysis if they were under age 18 years, discharged with a primary diagnosis relating to a psychiatric illness or had completed a survey in the previous 6 months. All subsequent events are assumed to incur the same utility decrement as in the primary event (Table 5). 
Table 5. Health-related Utility Decrements (EQ-5D) and Associated End Points

\begin{tabular}{|c|c|c|c|}
\hline \multirow[t]{2}{*}{ Event } & \multicolumn{2}{|c|}{ Utility Decrement } & \multirow[t]{2}{*}{ Source } \\
\hline & Primary & Subsequent & \\
\hline \multicolumn{4}{|l|}{ Macrovascular } \\
\hline Ischemic Heart Disease & 0.090 & 0.090 & UKPDS $62^{32}$ \\
\hline Myocardial Infarction & 0.066 & 0.066 & HODaR Survey ${ }^{47}$ \\
\hline Congestive Heart Failure & 0.108 & 0.108 & UKPDS 62 \\
\hline Stroke & 0.114 & 0.114 & HODaR Survey \\
\hline \multicolumn{4}{|l|}{ Microvascular } \\
\hline Pre-blind & 0.029 & 0.029 & HODaR Survey \\
\hline Blind & 0.074 & 0.074 & UKPDS 62 \\
\hline End-state Renal Disease & 0.263 & 0.263 & UKPDS 62 \\
\hline Dialysis & 0.305 & 0.305 & HODaR Survey \\
\hline Transplant & 0.075 & 0.075 & HODaR Survey \\
\hline Amputation & 0.280 & 0.280 & UKPDS 62 \\
\hline
\end{tabular}

UKPDS=United Kingdom Prospective Diabetes Study;

HODaR $=$ Health Outcomes Data Repository

The utility associated with hypoglycaemic events was modelled via multivariate regression models, relating the fear of hypoglycaemia to changes in health-related utility. ${ }^{16}$ The equations developed used pooled data from two postal surveys conducted in Cardiff, United Kingdom ( $n=1,305$ responses), in which the fear of hypoglycaemia was characterised using the fear of hypoglycaemia survey (FHS [eight question worry sub-scale only]) and health-related utility using the EQ-5D index.

The analysis revealed the FHS value to be the best estimate of the EQ-5D, while the number of hypoglycaemic events was found to be an important predictor of the FHS value. A two-stage approach was therefore adopted to predict EQ-5D; the relationship between frequency of hypoglycaemic events and FHS value was estimated, before estimating the EQ-5D using the predicted FHS value. Validation exercises proved the predictive power of the equations to be strong, with actual and predicted FHS score and EQ-5D values closely matched across all hypoglycaemia frequency and severity categories and across quartiles of the FHS.

Costs and benefits, measured in terms of Quality-Adjusted Life Years (QALYs), were assessed over a 40-year horizon and discounted at $3.5 \%$.

\section{RESULTS}

\section{Base Case}

The cost per QALY associated with insulin glargine treatment compared to insulin NPH was estimated at 40,101 TL under base case conditions. Per person, the lifetime difference in costs was estimated to be 7,140 TL, with an estimated benefit of 0.178 QALYs and a total of 52 hypoglycaemic events avoided. This translates to a cost of 137 TL per hypoglycaemic event avoided (Table 6). 
Table 6. Lifetime Results for a Cohort of 1,000 Patients Comparing Insulin Glargine to NPH Insulin Use

\begin{tabular}{|c|c|c|c|c|c|}
\hline \multirow[t]{2}{*}{ Scenario } & \multicolumn{3}{|c|}{ Lifetime Difference } & \multirow{2}{*}{$\begin{array}{l}\text { Costs (TL) per } \\
\text { Hypoglycaemic } \\
\text { Event Avoided }\end{array}$} & \multirow{2}{*}{$\begin{array}{l}\text { Costs (TL) } \\
\text { per QALY }\end{array}$} \\
\hline & $\begin{array}{l}\text { Total Costs } \\
\text { (TL) }\end{array}$ & $\begin{array}{c}\text { Total } \\
\text { QALYs }\end{array}$ & $\begin{array}{c}\text { Hypoglycaemic } \\
\text { Events* }\end{array}$ & & \\
\hline Base Case & 7139980 & 178 & -51976 & 137 & 40101 \\
\hline Gordon Demographics & 6350526 & 159 & -39374 & 161 & 40025 \\
\hline No HbA1c Benefit & 7181653 & 144 & -53394 & 134 & 49916 \\
\hline \multicolumn{6}{|c|}{ Dose-adjusted HbA1c Reduction } \\
\hline Overall & 8403624 & 200 & -50369 & 167 & 42071 \\
\hline Baseline $\mathrm{HbA} 1 \mathrm{c} \geq 8 \%$ & 8622668 & 220 & -49244 & 169 & 37756 \\
\hline Baseline $\mathrm{HbA} 1 \mathrm{c} \geq 10 \%$ & 8214494 & 261 & -72448 & 113 & 31418 \\
\hline
\end{tabular}

*Sum of all hypoglycaemic events (symptomatic, nocturnal and severe);

$\mathrm{HbA1c}=$ glycated heboglobin;

TL=Turkish Lira;

QALY=quality-adjusted life years

\section{Supplementary Analyses}

Further analysis implementing the demographic profile presented by Gordon $e t$ al. ${ }^{27}$ demonstrated only minor changes in the ICER value compared to the base case. Differences in mean age, gender, duration of diabetes, weight, and HbA1c at baseline resulted in a similar ICER of 40,025 TL.

Analysis evaluating the cost-effectiveness of glargine without improvement in glycaemic control associated with glargine resulted in an increased ICER. If no account is taken of the HbA1c benefit associated with glargine, no differences in the expected rates of diabetes-related conditions are expected between glargine and NPH. However, patients receiving glargine still experience clinical benefit in the form of fewer hypoglycaemic events than those on NPH.

Dose-adjusted improvements in glycaemic control were implemented in further analyses using therapy costs based on the weighted mean of dosages reported in Gordon et al. ${ }^{27}$ The mean HbA1c values for each subgroup at baseline were estimated from the reported risk factor profile; $10.0 \%$ and $11.1 \%$ for subgroups with baseline $\geq 8 \%$ and $\geq 10 \%$ respectively.

As HbA1c is a risk factor for cardiovascular disease, patients with improved glycaemic control are expected to experience fewer cardiovascular events. As the modelled reduction in HbA1c associated with glargine treatment increased for patients with a higher HbA1c level at baseline, the number of diabetes-related events avoided by these patients also increased. A greater number of diabetes-related events avoided due to glargine treatment compared to NPH, lead to a larger difference in QALYs and smaller difference in lifetime costs between the two insulins, and consequently improved cost-effectiveness results in these subsets of patients.

\section{Univariate Sensitivity Analysis}

One way sensitivity analysis on key model parameters showed the results to be most sensitive to large changes to the effectiveness of glargine with respect to hypoglycaemic events and to all costs (Table 7). 
Table 7. Sensitivity Analysis on Key Model Parameters for Glargine versus NPH

\begin{tabular}{|c|c|}
\hline Glargine vs. NPH Scenario & Cost/QALY \\
\hline Base Case & 40101 \\
\hline Age - 10 years & 42883 \\
\hline Age +10 years & 40628 \\
\hline Weight - $10 \mathrm{~kg}$ & 35460 \\
\hline Weight $+10 \mathrm{~kg}$ & 43772 \\
\hline \multicolumn{2}{|l|}{ Time Horizon } \\
\hline 5 years & 59289 \\
\hline 10 years & 50484 \\
\hline 20 years & 45213 \\
\hline 30 years & 40981 \\
\hline \multicolumn{2}{|l|}{ Discount Rate } \\
\hline $0 \%$ & 36367 \\
\hline $0 \%$ Benefits $/ 5 \%$ Costs & 19909 \\
\hline $3 \%$ Benefits $/ 3 \%$ Costs & 39581 \\
\hline $7 \%$ Benefits $/ 7 \%$ Costs & 43544 \\
\hline \multicolumn{2}{|l|}{ Utility Values } \\
\hline $50 \%$ Reduction of First year Decrement & 40177 \\
\hline $50 \%$ Reduction in Subsequent Year Decrements & 40714 \\
\hline \multicolumn{2}{|l|}{ Treatment Effects } \\
\hline $50 \%$ Reduction in Hypoglycaemia Efficacy & 67094 \\
\hline Severe Hypoglycaemia Risk Eduction $=0 \%$ & 83919 \\
\hline \multicolumn{2}{|l|}{ Event Costs } \\
\hline $50 \%$ Reduction of All Event Costs & 40721 \\
\hline $50 \%$ Increase of All Event Costs & 39482 \\
\hline \multicolumn{2}{|l|}{ All Costs (Events and Treatment) } \\
\hline $50 \%$ Reduction of All Costs & 20051 \\
\hline $50 \%$ Increase of All Costs & 60152 \\
\hline
\end{tabular}

$\mathrm{NPH}=$ neutral protamine Hagedorn; QUALY=quality adjusted life years

Varying the input values for age, weight and discount rate had only a minor effect on the overall result across all scenarios modelled. Similarly, reductions to the utility decrements associated with diabetes-related events had only a minor effect on the modelled outcome. Discounted costs $(5 \%)$ but not benefits resulted in relatively higher benefit and thus a decreased ICER (19,909 TL).

Reducing the time horizon led to an increased ICER, as the long-term benefit of fewer diabetes-related complications associated with glargine were not fully accounted for. The 50\% reduction in insulin glargine's hypoglycaemia efficacy had a negative effect on the model's results, with an increased ICER of 67,094 TL for glargine versus NPH. Setting the reduction of severe hypoglycaemia risk to zero percent had a greater impact on results, with an ICER of 83,919 TL versus NPH.

A reduction to all event costs in the model decreased the ICERs significantly; likewise an increase in all event and treatment costs increased the ICERs significantly. Indeed, the upper stored cost profile resulted in an ICER of 60,152 TL versus NPH. 


\section{DISCUSSION}

It is generally thought that severe hypoglycaemia is not as great a concern in patients with T2DM as in T1DM; however Leese et al. ${ }^{34}$ demonstrated the risk of experiencing a severe event requiring hospitalization was as important for T2DM patients receiving insulin as for T1DM patients.

Differential patterns of hypoglycaemia exist amongst different study or population types. For instance, randomised controlled trials (RCTs) have been shown to demonstrate lower levels of hypoglycaemia than observational studies as part of the 2006 Australian evaluation of insulin glargine presented to the Pharmaceutical Benefits Advisory Committee (PBAC). ${ }^{35}$ These differing event rates may be commensurate with outcomes from trials of intensified insulin therapy (IIT), which demonstrated that successfully achieving glycaemic control is associated with an increased burden of hypoglycaemia. Indeed the risk of severe hypoglycaemic events increased up to threefold over 'conventional' therapy. ${ }^{13,36}$

Despite the failure of conventional meta analyses ${ }^{37,38}$ of RCT results to identify clinically meaningful benefit of glargine over NPH, several randomised trials ${ }^{21,39,40,41,42}$ and well-specified observational studies ${ }^{43}$ report up to a $66 \%$ rate reduction ${ }^{40}$ in all types of hypoglycaemic events in conjunction with a reduction in HbA1c of up to $0.5 \%$. Furthermore, meta-regression analysis has successfully demonstrated the effect of glargine on the relationship between HbA1c and hypoglycaemia. Mullins et al. ${ }^{29}$ defined this relationship using pooled data from all phase III to IV clinical trials comparing glargine and NPH.

Insulin glargine produces clinical benefits for patients with T2DM through the reduction of both HbA1c levels and hypoglycaemic events. The lifetime risk of macro- and micro-vascular events is reduced as a result of improved glycaemic control, leading to long-term life expectancy and quality of life gains. Further improvements in quality of life are achieved through the avoidance of hypoglycaemic events, which may also have positive implications for the timely initiation of insulin therapy, patient compliance and persistence of therapy.

It is difficult to interpret the results of the cost-effectiveness analysis because there is no official costeffectiveness threshold in Turkey, since cost utility analyses are not considered valid for the reimbursement of pharmaceuticals. However, the results of the present analysis can be usefully analysed using thresholds calculated using methodology from the World Health Organization (WHO), as follows:

Therapy is very cost-effective if the ICER is less than GDP per capita (app. 18,950 TL), is cost-effective if the ICER is between one and three times GDP per capita (app. 18,950-56,850 TL) and is not cost-effective if the ICER is greater than three times GDP per capita (app. 56,850 TL) (GDP per capita estimated by IMF). ${ }^{30}$

More generally, in European cost-effectiveness studies as a whole, it is generally agreed that an intervention that provides one extra year of quality-adjusted life at a cost of $€ 30,000$ provides good value, although explicit cost-effectiveness thresholds are rarely stated. ${ }^{44}$ This equates to almost 69,500 TL (2012 average exchange rate: $€ 1=2.3135 \mathrm{TL}){ }^{45}$

Insulin glargine can thus be considered cost-effective compared to NPH under base case conditions, as the ICER of 40,101 TL was well below the cost-effectiveness threshold typically applied in Europe, or derived using WHO methodology. Insulin glargine can also be considered cost-effective under all scenarios modelled as part of supplementary analysis and the majority of univariate sensitivity analyses conducted.

An increase of all costs (event and treatment) by $50 \%$ or reduction in the efficacy of glargine with respect 
to hypoglycaemia by 50\%, result in ICER values within the range typically accepted as cost-effective in Europe, however in excess of the threshold derived according to WHO methodology. Reducing the effect of glargine on severe hypoglycaemia to zero was the only tested scenario under which glargine cannot be considered costeffective compared to NPH, as the ICER exceeds both the thresholds corresponding to $3^{*}$ GDP and typically applied in Europe.

Weight is known to have significant implications for quality of life, mortality and health related costs. ${ }^{46}$ However, the model does not simulate changes in patient weight as a result of either natural progression or initiation of insulin therapy. Weight is a recognised risk factor for cardiovascular events and indeed is included in the UKPDS $68^{24}$ equation here used to predict the incidence of congestive heart failure. Furthermore, fears regarding weight gain as a result of treatment have been shown to be a significant factor inhibiting medication adherence in T2DM patients. ${ }^{15}$

A number of studies have reported comparable ${ }^{19,21}$ or smaller ${ }^{20}$ weight gains associated with insulin glargine compared to NPH. Comparisons made by Gordon et al. ${ }^{27}$ showed that while patients on all assessed regimens generally gained weight over the first 12 months, the increase in weight associated with insulin glargine was smaller than with NPH (mean $1.9 \mathrm{~kg}$ with glargine vs. $2.3 \mathrm{~kg}$ with NPH). Thus the inclusion of weight changes at initiation of insulin would not be expected to result unfavourably on the cost-effectiveness results reported in this analysis.

Where data are available, inputs specific to the Turkish population have been utilised, however this does not extend to the HbA1c efficacy data obtained from the United Kingdom. The management of T2DM in Turkey is likely to be similar to that of the United Kingdom, since clinicians follow an incremental approach to therapy, often refer to international guidelines and will encounter similar barriers to therapy progression. The use of observational data from clinical practice is particularly useful in view of the recognised disparity between guidelines and clinical practice.

\section{CONCLUSION}

Results of the modelling conducted suggest that insulin glargine may be considered cost-effective compared to NPH in a Turkish setting, based on methodology proposed by WHO and also the threshold typically applied in Europe. Insulin glargine is expected to be most cost-effective in patients with higher HbA1c levels at baseline and to remain cost-effective compared to $\mathrm{NPH}$, even when the HbA1c benefits associated with glargine are not accounted for.

\section{ACKNOWLEDGEMENTS}

Phil McEwan and colleagues developed the model used in this analysis and Richa Goyal Rai conducted background research contributing to the manuscript's introduction.

\section{Conflict of Interest Declaration}

The study was supported by Sanofi Turkey, by whom T. Sahin and D. Ozkaya are employed. H. Bennett acted as consultant to Sanofi Turkey. 


\section{REFERENCES}

1 Whiting DR, Guariguata L, Weil C, et al. IDF Diabetes Atlas: Global estimates of the prevalence of diabetes for 2011 and 2030. Diabetes Res Clin Pract 2011;94;311-21

${ }^{2}$ Satman I, Tutuncu Y, Gedik S et al. and the TURDEP-II Study Group. Diabetes epidemic in Turkey: Results of the second population based survey of diabetes and risk characteristics in Turkey (TURDEP-II). 47th EASD Annual Meeting, Poster: A-11-2498, 12-16 Sept, Lisbon (2011). Diabetologia 2011;54(Suppl 1):P2498.

${ }^{3}$ Onat A, Hergenc G, Uyarel H, et al. Prevalence, incidence, predictors and outcome of type 2 diabetes in Turkey. Anadolu Kardiyol Derg 2006;6:314-21.

${ }^{4}$ IDF. Promoting diabetes care, prevention and a cure worldwide 2008. http://www.idf.org/webdata/docs/ idf-europe/Country\%20report\%20TURKEY\%20pub.pdf. Accessed March 142012.

${ }^{5}$ Wright A, Burden AC, Paisey EB, et al. Sulfonylurea inadequacy: efficacy of addition of insulin over 6 years in patients with type 2 diabetes in the U.K. Prospective Diabetes Study (UKPDS 57). Diabetes Care 2002;25:3306.

${ }^{6}$ Gaede P, Vedel P, Larsen N, et al. Multifactorial intervention and cardiovascular disease in patients with type 2 diabetes. N Engl J Med 2003;348:383-93.

${ }^{7}$ Home PD, Boulton AJM, Jimenez J, et al. Issues relating to the early or earlier use of insulin in type 2 diabetes. Practical Diabetes Int 2003;20:63-71.

8 Inzucchi SE, Bergenstal RM, Buse JB, et al. Management of hyperglycemia in type 2 diabetes: a patientcentered approach. Position statement of the American Diabetes Association (ADA) and the European Association for the Study of Diabetes (EASD). Diabetologia. 19 April 2012 [Epub ahead of print]

9 Yenigun M, Oruk G, Dayan A, et al. Clinical experience on insulin detemir in Turkey: efficacy and safety data from the Predictive Study. Turk Jem 2008;12:91-6.

${ }^{10}$ Society of Endocrinology and Metabolism of Turkey (SEMT). Clinical practice guidelines for diagnosis, treatment and follow-up of diabetes mellitus and its complications. Turkish J Endocrinol Metabolism 2010;14(Suppl):1-127.

${ }^{11}$ Sreenan S, Yenigun M, Robinson A, et al. HbA1c levels exceed recommended targets prior to initiation or intensification of insulin therapy in clinical practice: baseline data from the PREDICTIVE European cohort. EASD 2006, Abstract 0897.

${ }^{12}$ Satman I, Imamoglu S, Yilmaz C. Physician adherence to the SEMT guidelines for the management of type 2 diabetes in Turkey: ADMIRE study. Turkish J Endocrinol Metabolism 2010;14(3):66-72.

${ }^{13}$ The Diabetes Control and Complications Trial Research Group. The effect of intensive treatment of diabetes on the development and progression of long-term complications in insulin-dependent diabetes mellitus. $N$ Engl J Med 1993;329:977-86.

${ }^{14}$ Turner RC, Milns H, Neil HA, et al. Risk factors for coronary artery disease in non-insulin dependent diabetes mellitus: United Kingdom Prospective Diabetes Study (UKPDS: 23). BMJ 1998;316:823-8.

${ }^{15}$ Farmer A, Kinmonth AL, Suton S. Measuring beliefs about taking hypoglycaemic medication among people with type 2 diabetes. Diabet Med 2006;23:265-70.

${ }^{16}$ Currie CJ, Morgan C Ll, Poole CD, et al. Multivariate models of health-related utility and the fear of hypoglycaemia in people with diabetes. Curr Med Res Opin 2006;22:1523-34.

${ }^{18}$ Fach EV, Busch K, Anderesi Z, et al. HOE901/4004 Study Group: efficacy of insulin glargine in Type 2 diabetes: effect at different stages of diabetes. Diabetes 2004;53:A124. 
${ }^{19}$ Riddle M, Rosenstock J, Gerich J. The Treat-to-Target Trial: randomized addition of glargine or human NPH insulin to oral therapy of type 2 diabetic patients. Diabetes Care 2003;26:3080-6.

${ }^{20}$ Rosenstock J, Schwartz SL, Clark CM, et al. Basal insulin therapy in Type 2 diabetes 28-week comparison of insulin glargine (HOE 901) and NPH insulin. Diabetes Care 2001;24:631-6.

${ }^{21}$ Yki-Järvinen H, Dressler A, Ziemen M. Less nocturnal hypoglycaemia and better post-dinner glucose control with bedtime insulin glargine (HOE 901) versus NPH insulin during combination therapy in type 2 diabetes. Diabetes Care 2000;23:1130-6.

${ }^{22}$ Fritsche A, Schweitzer MA, Häring H. Improved glycaemic control and reduced nocturnal hypoglycaemia in patients with type 2 diabetes with morning administration of insulin glargine compared with NPH insulin. Diabetes Care 2002;51(Suppl 2):A54.

${ }^{23}$ McEwan P, Poole CD, Tetlow T, et al. Evaluation of the cost-effectiveness of insulin glargine versus NPH insulin for the treatment of type 2 diabetes in the UK. Curr Med Res Opin 2007;23(Suppl 1):21-31.

${ }^{24}$ Clarke PM, Gray AM, Briggs A, et al. A model to estimate the lifetime health outcomes of patients with type 2 diabetes: the United Kingdom Prospective Diabetes Study (UKPDS) Outcomes Model (UKPDS 68). Diabetologia 2004;47:1747-59.

${ }^{25}$ IDMPS 2009. Statistical report: An international registry to assess the current medical practice in patients with diagnosis of diabetes mellitus. Cross-sectional Study - Wave 2007 - Turkey

${ }^{26}$ NICE technology appraisal: Diabetes (types 1 and 2) - long acting insulin analogues (TA53). http://www. nice.org.uk/page.aspx?o=TA053. Accessed April 15, 2006.

${ }^{27}$ Gordon J, Pockett RD, Tetlow AP, et al. A comparison of intermediate and long-acting insulins in people with type 2 diabetes starting insulin: an observational database study. Int J Clin Pract 2010;64:1609-18.

${ }^{28}$ Riddle et al. Treatment to target study: insulin glargine vs NPH insulin added to oral therapy of Type 2 diabetes: successful control with less nocturnal hypoglycaemia. 62nd Sci Sess Am Diabetes Assoc (ADA), June 2002, Diabetes 2002; 51 (suppl 2): A113, abs 457-P.

${ }^{29}$ Mullins P, Sharplin P, Yki-Jarvinen H, et al. Negative binomial meta-regression analysis of combined glycosylated hemoglobin and hypoglycemia outcomes across eleven phase III and IV studies of insulin glargine compared with neutral protamine Hagedorn insulin in type 1 and type 2 diabetes mellitus. Clin Ther 2007;29:8.

${ }^{30}$ International Monetary Fund. World economic outlook (WEO) database. October 2012 Edition. [http:// www.imf.org/external/pubs/ft/weo/2012/02/weodata/index.aspx] Accessed January 5, 2013.

${ }^{31}$ Ministry of Health of Turkey. General Directorate of Pharmaceuticals and Pharmacy Price List. http:// www.iegm.gov.tr/Default.aspx?sayfa=fiyat_listesi. Accessed November 15, 2012.

${ }^{32}$ Clarke P, Gray A, Holman R. Estimating utility values for health states of type 2 diabetic patients using the EQ-5D (UKPDS 62). Med Decis Making 2002;4:340-9.

${ }^{33}$ Currie CJ, McEwan P, Peters JR, et al. The routine collation of health outcomes data from hospital treated subjects in the Health Outcomes Data Repository (HODaR): descriptive analysis from the first 20,000 subjects. Value Health 2005;8:581-90.

${ }^{34}$ Leese GP, Wang J, Broomhall J, et al. Frequency of severe hypoglycaemia requiring emergency treatment in type 1 and type 2 diabetes: a population-based study of health service resource use. Diabetes Care 2003;26:117680. 
${ }^{35}$ Pharmaceutical Benefits Advisory Committee (PBAC). Public Summary Document - Insulin Glargine March 2006. http://www.health.gov.au/internet/main/publishing.nsf/Content/pbac-psd-insulinglarginemar06. Accessed November 15, 2012.

${ }^{36}$ Reichard P, Nilsson B-Y, Rosenquist U. The effect of intensive treatment of diabetes on the development and progression of long-term complications in insulin-dependent diabetes mellitus. N Engl J Med 1993;329:3049.

${ }^{37}$ Warren E, Weatherley-Jones E, Chilcott J, et al. Systematic review and economic evaluation of a long-acting insulin analogue, insulin glargine. Health Technol Assess 2004;8(45).

${ }^{38}$ Medical Research Matters. Insulin glargine and insulin detemir for type 1 and type 2 diabetes: Systematic review of randomised controlled trials. Report for Sanofi-aventis, January 2006.

${ }^{39}$ Pieber TR, Eugene-Jolchine I, Derobert E. Efficacy and safety of HOE901 versus NPH insulin patients with type 1 diabetes. Diabetes Care 2000;23:157-62.

${ }^{40}$ Ratner R, Hirsch IB, Niefing JL, et al. Less hypoglycaemia with Lantus in intensive insulin therapy for Type 1 diabetes. Diabetes Care 2000;23:639-43.

${ }^{41}$ Fulcher GR, Gilbert RE, Yue DK. Glargine is superior to neutral protamine Hagedorn for improving glycated haemoglobin and fasting blood glucose levels during intensive insulin therapy. Intern Med J 2005;35:536-42.

${ }^{42}$ Porcellatti F, Rossetti P, Pampanelli S, et al. Better long-term glycaemic control with the basal insulin glargine as compared with NPH in patients with Type 1 diabetes mellitus given meal-time lispro insulin. Diabet Med 2004;21:1213-20.

${ }^{43}$ Gallen I and Carter C. Prospective audit of the introduction of insulin glargine (Lantus) into clinical practice in type I diabetes. Practical Diabetes Int 2004;21:110-14.

${ }^{44}$ Scherbaum WA, Goodall G, Erny-Albrecht KM, et al. Cost-effectiveness of pioglitazone in type 2 diabetes patients with a history of macrovascular disease: a German perspective. Cost-effectiveness Res Allocation 2009;7:9.

${ }^{45}$ European Central Bank. Statistical Data Warehouse http://sdw.ecb.europa.eu/home.do. Accessed January 15, 2013.

${ }^{46}$ Counterweight Project Team. Influence of body mass index on prescribing costs and potential cost savings of a weight management programme in primary care. J Health Serv Res Policy. 2008;13:158-66.

${ }^{47}$ Morgan CL, McEwan P, Morrissey M, et al. Characterisation and comparison of health related utility in people with diabetes in various states of single and multiple vascular complications. Diabet Med 2006;23:11005. 